\title{
Field Evaluation and Selection for Resistance to Aster Yellows in Carrot (Daucus carota L.)
}

\author{
W.H. Gabelman, I.L. Goldman, and D.N. Breitbach \\ Department of Horticulture, University of Wisconsin-Madison, 1575 Linden Drive, Madison, WI 53706
}

Additional index words. carrot breeding, aster leafhopper, mycoplasma-like organism, breeding for disease resistance

\begin{abstract}
Aster yellows, an insect-vectored disease caused by a mycoplasma-like organism (MLO), is a destructive vegetable plant disease in the upper midwestern United States. A breeding effort was initiated in 1982 to develop aster yellows resistance in carrot. An aster yellows synthetic (AYSYN) population composed of four standard open-pollinated cultivars and five inbred lines was assembled in 1982. Inbred lines were extracted from the AYSYN population using a variety of methods. Selection in naturally and artificially infested field sites was carried out from 1982 to 1989. Twentythree carrot germplasm lines inbred for a minimum of five generations and three hybrids were developed from the AYSYN population during the selection process. Replicated field experiments were conducted in 1990, 1991, and 1993 to determine the relative aster yellows resistance of these 26 selected lines compared with six commonly grown carrot cultivars. Susceptibility was based on the presence of disease symptoms on carrot shoots. Data were collected as percent aster yellows infection based on the presence or absence of crown shoots on each plant. Averaged over years, significant differences were detected for percent aster yellows infection among carrot genotypes. Breeding lines selected for resistance ranged from $2.5 \%$ to $35.3 \%$ infected plants per plot averaged over years, while standard cultivars ranged from $12 \%$ to $42 \%$ infected plants per plot. Significant reductions in aster yellows infection were observed in many selected lines compared to standard cultivars. Results demonstrate the effectiveness of inbreeding and selection for aster yellows resistance. This breeding effort represents the first report of aster yellows-resistant carrot germplasm.
\end{abstract}

Carrot is a major vegetable crop with worldwide importance for caloric intake and nutrition. In the past 20 years, aster yellows, a disease caused by a mycoplasma-like organism (MLO), has become a limiting factor to carrot production in several regions of the upper midwestern United States (Arcelin and Kushalappa, 1991; Schultz, 1973; Zalom, 1981). Despite many reports of disease symptomology and MLO characterization, quantitative aspects of aster yellows epidemiology have been studied in little detail. Although the entire carrot crop is susceptible to aster yellows infection, there are no carrot cultivars, open-pollinated populations, or inbreds with known resistance to aster yellows. The development of aster yellows-resistant carrot germplasm would be useful to carrot producers for reducing pesticide use and to carrot breeders for improving host-plant resistance to this disease.

Aster yellows has a very broad host range, which includes cereals (Chiykowski, 1967), strawberry (Chiykowski, 1987), lettuce (Linn, 1940), endive (Linn, 1940), and celery (Chiykowski, 1977). Disease severity in the upper midwestern United States is more acute, especially on muck soils. Aster yellows symptoms typically develop $\approx 2$ weeks after inoculation by the aster yellows leafhopper, Macrosteles fascifrons. Typical disease symptoms include stunting, yellowing, leaf bronzing, yellow shoots developing from the crown, sterility, leaf-like petals, and witch's broom growth via profuse production of vegetative shoots or lateral branches. Foliar yellowing starts with vein clearing of new leaves and proceeds to a systemic yellowing. Hypertrophy and hyperplasia of phloem, caused by general necrosis of phloem tissue, is often observed in aster yellows-infected plants (Struckmeyer, 1963). This results in the production of additional sieve elements (Girolami,

Received for publication 24 Jan. 1994. Accepted for publication 19 May 1994. This research supported by the Wisconsin Carrot Grower's Association, the Wisconsin Muck Grower's Association, the Midwest Food Processor's Association, and Hatch projects 1025 and 3654, Wisconsin Agricultural Experiment Station, College of Agricultural and Life Sciences, Univ. of Wisconsin-Madison. The cost of publishing this paper was defrayed in part by the payment of page charges. Under postal regulations, this paper therefore must be hereby marked advertisement solely to indicate this fact.
1955). The appearance of new growth is characterized by yellow, elongated shoots emanating from the crown. Aster yellows infection in carrot in Wisconsin often manifests itself by three primary symptoms: leaf bronzing, crown shoot proliferation, and extensive root-hair growth. Since these symptoms are highly correlated, above-ground symptoms could be effectively used to screen carrot germplasm for aster yellows resistance. Susceptibility to aster yellows in this investigation was characterized phenotypically by the degree to which carrot shoots exhibited disease symptoms when grown in the presence of infected aster leafhoppers.

The plant-to-plant spread of aster yellows is accomplished by aster leafhoppers. The aster leafhopper is the primary source of the disease-causing MLO. Leafhoppers migrate northward from southern breeding areas each spring. Migratory patterns, feeding habits, environmental conditions, and host-plant preference all play a role in the spread of aster yellows. In the upper midwestern United States, early spring infections are directly correlated with the arrival of migratory leafhoppers carrying a MLO from the southern United States, where they overwinter. Environmental factors influencing development and spread of aster yellows include temperature, light, plant nutrition, and water balance (Braun and Sinclair, 1976; Kunkel, 1926; McCoy, 1976; Zelcer et al. 1972).

Since no resistant cultivars are known, aster yellows control has traditionally been accomplished through chemical sprays that eradicate or reduce aster leafhopper populations. Insecticides controlling the aster leafhopper are recommended in all areas infested with aster yellows. Growers are also able to control leafhopper populations through the prediction method described by Chiykowski and Chapman (1965). The prediction method enables growers to time insecticidal sprays more accurately and thereby reduce pesticide use. Despite the potential to control leafhoppers with insecticides, failure to reduce pesticide use may have detrimental consequences for cropping environments. The development of aster yellows-resistant carrot germplasm may reduce chemical use in carrot production and possibly eliminate the need for chemical sprays to control the aster leafhopper. The objective of this investigation was to compare carrot breeding lines 
selected for aster yellows resistance against standard cultivars under field conditions for aster yellows resistance.

\section{Materials and Methods}

Cultural practices. Infected aster leafhoppers were collected from agricultural sites in the southern United States during Spring 1990, 1991, and 1993 by J. Wyman, Dept. of Entomology, Univ. of Wisconsin. These leafhoppers had fed on MLO-infected cereals during the winter and early spring and were able to spread aster yellows. Leafhoppers were placed in enclosed wooden containers containing oat plants in the greenhouse. Large infective populations of leafhoppers were obtained by allowing nymphs (first to fifth instar) and adults 10 days access to feeding on aster yellowsinfected plants, including various aster yellows-susceptible weeds (pineapple weed and dodder). About 50 plants in each $66 \times 46 \times 46-$ $\mathrm{cm}$ frame were used to establish several thousand infective leafhoppers. Aspirators were used to extract leafhoppers from frames. Leafhoppers were transferred to covered plastic containers and transported to field plots where they were evenly distributed by hand throughout the field. Insect cultures were used for 2 to 3 weeks.

In pilot investigations, leafhopper populations were sampled during the season with insect nets. Methods recommended by Schultz (1973) suggested accurate leafhopper counts could be obtained by periodic sweeps in each row of carrots. Initially, 25 sweeps were made in each row 3 times during the growing season. Leafhoppers were sacrificed with chloroform and counted in a sectored pan as described by Shultz (1973). Results of leafhopper population studies demonstrated uniform spatial distribution during the field experiment.

Carrot accessions were planted in a four-row bed $4 \mathrm{~m}$ long with $30 \mathrm{~cm}$ between rows. Each four-row bed was bordered by rows of lettuce (Fig. 1). Breeding lines and standard cultivars were assigned to plots in a randomized complete-block design with four blocks. In the upper midwestern United States, the preferred host for the aster leafhopper is lettuce (Peterson and Saini, 1964; Schultz, 1973). This technique ensured adequate leafhopper populations for infection. Leafhoppers were released on lettuce plants during late June and early July and distributed evenly throughout the field. Broadleaf weeds were controlled by a preemergent spray of linuron at $800 \mathrm{~g} \cdot \mathrm{ha}^{-1}$, and all supplemental weeding was done by hand. Plots were rated for percent aster yellows infection in the first week of October of each year. Ratings were based on the percentage of plants per plot exhibiting a proliferation of crown shoots. Crown shoots are defined as thin, chlorotic petioles originating from the root crown. The most characteristic symptom of aster yellows is a proliferation of yellow crown shoots, and this proliferation has been identified as the most dependable symptom for scoring aster yellows-infected plants (W.H. Gabelman, unpublished data). The aster yellows score was calculated by dividing the number of plants displaying aster yellows symptoms by the total number of plants per plot. Percent infection per plot values were $\log _{10}$ transformed to improve normality and subjected to analysis of variance. An F-protected LSD value was calculated for comparing means.

Genetic materials. Two-hundred entries comprising open-pollinated cultivars and inbred lines from diverse sources were screened for aster yellows resistance in the field in 1982. These entries were comprised of adapted and unadapted carrot germplasm. The top $10 \%$ was selected based on resistance scores, and 189 roots from these lines were planted in the greenhouse after vernalization. From this group, 20 roots that flowered successfully were placed in a greenhouse pollination cage. These twenty roots included a single root from each of five inbred lines (derived from crosses among W33, W263, W266, and W93), six inbred roots descended from a double cross (OSU260 crossed with an $\mathrm{F}_{1}$ of an unnamed Russian line and W33), and four open-pollinated cultivars (Royal Chantenay, Scarlet Nantes, Gold King, and Nanco). The inbred lines were developed in the Univ. of Wisconsin carrot breeding program (WBP), except OSU260, which was developed at Oregon State Univ. All open-pollinated cultivars were developed by Northrup King Co., except 'Nanco', which was obtained from the Vilmorin Seed Co. At flowering, intermating was carried out by fly-mediated pollen transfer. Seed was harvested from each of the entries separately. This seed was used to form the Wisconsin aster yellows synthetic (AYSYN) population. The AYSYN population was used to develop aster yellows-resistant carrot inbreds. Inbred lines were extracted from the AYSYN population by two schemes and from breeding lines not part of the AYSYN population by one scheme (Fig. 2, Table 2).

Inbred lines were derived using three primary methods. The first method involved selecting a minimum of four roots from a collection of inbred lines in the WBP with good resistance to aster yellows. These roots were intermated and inbred for eight generations and represent the only group not derived from the AYSYN population. A single inbred line was developed in this manner and designated 'W1-1'. AYSYN population-derived inbred lines were developed using three related methods: from inbred progeny of the AYSYN population (2a), from AYSYN-derived inbred lines intermated with inbred selections from the AYSYN population (2b), or from high-color inbred lines intermated with the AYSYN population (2c). All AYSYN lines were inbred for a minimum of five generations. The AYSYN hybrids consisted of two categories: hybrids for which both parents were selections from the AYSYN population (3a) and hybrids for which one parent is derived from the AYSYN population and the other parent is a high-color inbred line (3b).

\section{Results}

The analysis of variance revealed a highly significant year $x$ genotype interaction (Table 1). Few changes in genotype rankings

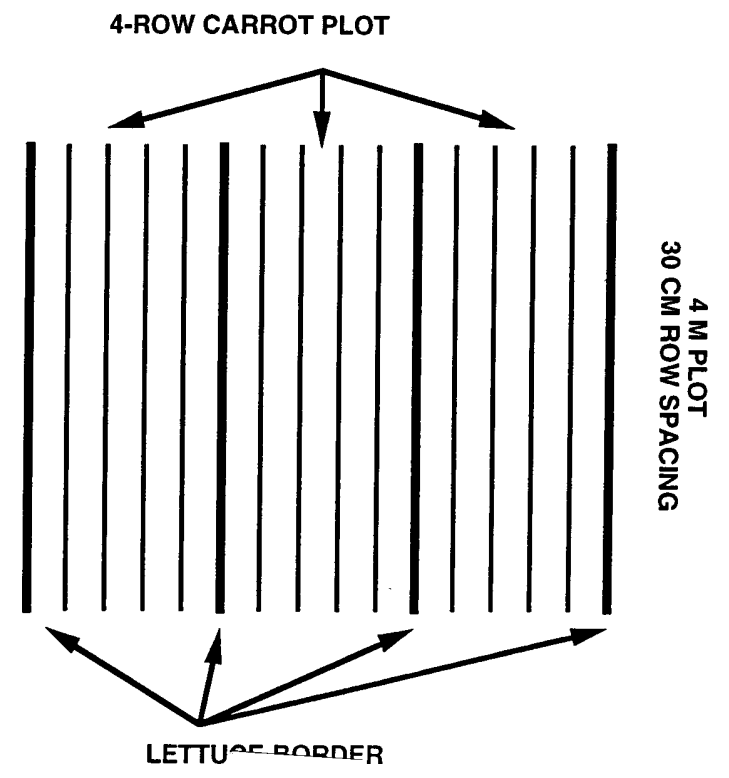

Fig. 1. Diagrammatic representation of field design for carrot aster yellows trials. 
over years were measured; thus, this interaction was due to changes in magnitude of means among the 3 years. Data were combined over years for statistical analyses. Highly significant differences were detected among genotypes for percent infection per plot (Table 2). Averaged over 3 years, percent infection values ranged from 2.54 to 42.04 (Table 2). The most resistant inbred line resulting from the selection program exhibited a 16-fold decrease in percent aster yellows infection compared to the most susceptible standard cultivar. In general, inbred lines derived from the WBP showed significantly lower percent infection per plot than standard cultivars. The mean performance of all lines was $11.96 \%$ infection per plot, whereas the six standard cultivars exhibited a mean of $24.3 \%$ infection per plot. These data suggest a significant reduction in aster yellows infection of inbred lines compared to standard cultivars. 'Scarlet Nantes', 'Royal Chantenay', and 'Gold King' exhibited the lowest percent infection per plot, while 'Danvers 126', 'Py-60', and 'Spartan Bonus 80' were significantly more infected. The three most resistant cultivars were used as parental materials in the AYSYN population, thus it is likely that they contributed genes for resistance to the AYSYN population.

Leafhopper counts taken at these field sites during the initial evaluation of genotypes for the AYSYN population indicated comparable populations of aster leafhoppers on diverse genotyopes throughout the field (Schultz, 1973). This finding suggests that the mechanism of aster yellows resistance may not be reduced foliar feeding. Preliminary leafhopper counts in mixed fields of inbred lines selected for resistance and standard cultivars indicated uniform distribution of leafhoppers throughout the field. No genotypic feeding preferences were observed in these studies.

\section{Discussion}

The inbred lines tested in this investigation were developed using three schemes (Fig. 2). Although comparisons among inbreds based on their method of derivation are unbalanced due to differences in the number of lines from each group and large variation

Wisconsin Aster Yellows Resistant Germplasm
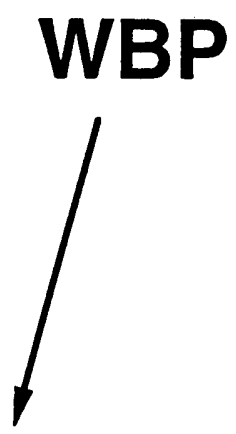

INBRED GROUP 1

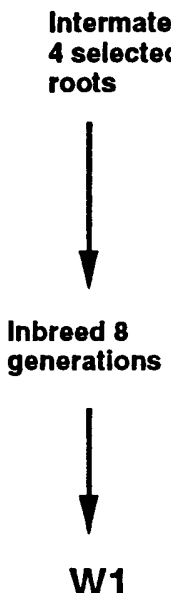

\section{AYSYN}
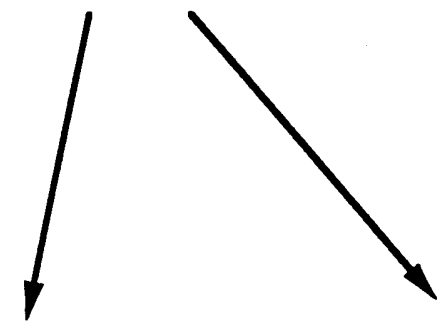

INBRED GROUP 2 HYBRID GROUP

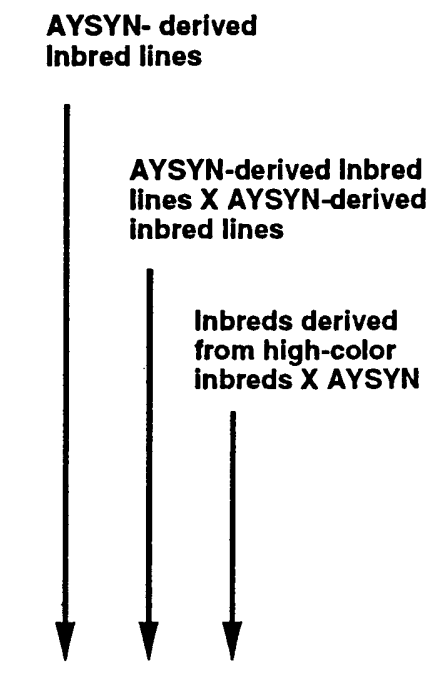

Inbred lines

derived from AYSYN

in hybrid combination

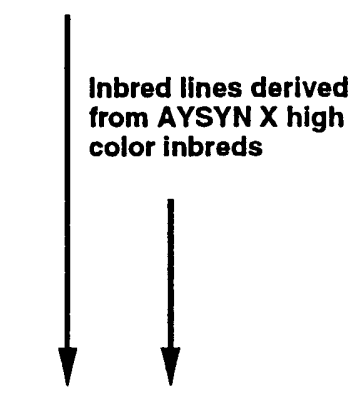

W3a W3b

Inbreed 5 generations

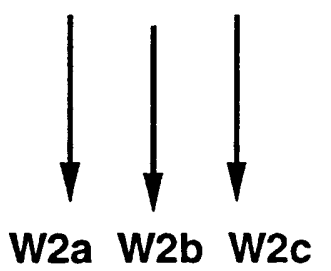

Fig. 2. Development scheme for inbred lines and hybrids from the Wisconsin aster yellows synthetic (AYSYN) population. WBP = University of Wisconsin carrot breeding program. Details on inbreeding and intermating are given in Materials and Methods. 
Table 1. Mean squares from the combined analysis of variance for percent aster yellows infection per plot of 32 carrot genotypes grown in the presence of aster yellows-infected leahoppers for 3 years at Madison, Wis.

\begin{tabular}{lccc}
\hline \hline Source of variation & df & Mean square & F value \\
\hline Year & 2 & 11.10 & $164.2^{* *}$ \\
Block & 3 & 0.62 & $9.1^{* *}$ \\
Genotype & 31 & 0.93 & $13.7^{* *}$ \\
Block $\times$ genotype & 93 & 0.06 & 0.9 \\
Year $\times$ genotype & 44 & 0.17 & $2.5^{* *}$ \\
\hline
\end{tabular}

${ }^{*, * *}$ Significant at $P<0.05$ or 0.01 , respectively

Table 2. Mean percent aster yellows infection per plot of 32 carrot genotypes grown in the presence of aster yellows-infected leahoppers for 3 years at Madison, Wis.

\begin{tabular}{|c|c|c|}
\hline Line & Source & $\begin{array}{c}\text { Infection/plot } \\
(\%)\end{array}$ \\
\hline Danvers 126 & Asgrow Seed Co. & 42.04 \\
\hline Py-60 & Peter Edwards Seed Co. & 30.51 \\
\hline Scarlet Nantes & Northrup King Seed Co. & 14.63 \\
\hline Royal Chantenay & Northrup King Seed Co. & 19.01 \\
\hline Gold King & Northrup King Seed Co. & 12.26 \\
\hline Spartan Bonus 80 & Crookham Seed Co. & 27.31 \\
\hline $\mathrm{W} 1-1$ & Wisconsin breeding program & 7.95 \\
\hline W2a-1 & Wisconsin breeding program & 9.63 \\
\hline W2a-2 & Wisconsin breeding program & 17.76 \\
\hline W2a-3 & Wisconsin breeding program & 2.54 \\
\hline W2a-4 & Wisconsin breeding program & 8.49 \\
\hline W2a-5 & Wisconsin breeding program & 3.82 \\
\hline W2a-6 & Wisconsin breeding program & 5.85 \\
\hline W2a-7 & Wisconsin breeding program & 6.28 \\
\hline W2a-8 & Wisconsin breeding program & 12.93 \\
\hline W2b-1 & Wisconsin breeding program & 7.13 \\
\hline W2b-2 & Wisconsin breeding program & 15.71 \\
\hline $\mathrm{W} 2 \mathrm{c}-1$ & Wisconsin breeding program & 12.59 \\
\hline $\mathrm{W} 2 \mathrm{c}-2$ & Wisconsin breeding program & 12.08 \\
\hline W2c-3 & Wisconsin breeding program & 32.35 \\
\hline W3a-1 & Wisconsin breeding program & 10.26 \\
\hline W3a-2 & Wisconsin breeding program & 7.10 \\
\hline W3a-3 & Wisconsin breeding program & 9.20 \\
\hline W3a-4 & Wisconsin breeding program & 13.49 \\
\hline W3a-5 & Wisconsin breeding program & 18.80 \\
\hline W3a-6 & Wisconsin breeding program & 15.35 \\
\hline W3a-7 & Wisconsin breeding program & 4.08 \\
\hline W3a-8 & Wisconsin breeding program & 9.61 \\
\hline W3a-9 & Wisconsin breeding program & 19.33 \\
\hline W3a-10 & Wisconsin breeding program & 18.54 \\
\hline W3b-1 & Wisconsin breeding program & 15.05 \\
\hline W3b-2 & Wisconsin breeding program & 14.99 \\
\hline LSD 0.05 & & 3.32 \\
\hline
\end{tabular}

among infection scores within a group, several interesting trends may be noted. The most successful scheme for selecting aster yellows-resistant inbreds (as measured by the number of lines with low infection scores) was the use of the AYSYN population as a source of inbreds either directly or in combination (W2a, W2b). Generally of lesser success was the use of hybrid combinations of inbred lines derived from the AYSYN population (W3a, W3b). While conclusions regarding these trends should not be made, this finding may suggest that the best way to use such a synthetic population in the initial phases of selection was to combine it with already-established inbred lines. No advantage was measured for percent infection among hybrids (W3a, W3b) compared to inbreds; however, these hybrids were composed primarily of inbred lines selected from the AYSYN population. Resistant inbreds in hybrid combination with elite inbred lines may lead to the development of superior resistant hybrid cultivars.

In addition to breeding strategy, two other factors played an important role in developing resistant inbred lines. First, all inbred lines evaluated in this investigation were inbred by intermating four or more selected plants for a minimum of five generations before testing. While it is still not known how aster yellows resistance is controlled genetically, inbreeding may have uncovered recessive alleles that condition resistance. Second, selecting in a naturally and artificially infested field site contributed to increased levels of resistance in these inbred lines. The relative isolation of this field site resulted in little potential for carryover of insecticidal sprays. High aster leafhopper populations were obtained by natural infection and maintained by artificial infection, thus ensuring strong selection pressure for resistance while avoiding escapes. Because three of the cultivars used in this investigation ('Scarlet Nantes', 'Royal Chantenay', and 'Gold King') were developed by Northrup King Seed Co. in Stanton, Minn., it is likely that natural populations of aster leafhoppers present in Minnesota contributed to the relatively high level of aster yellows resistance in these materials. Averaged together, these three cultivars exhibited $15.3 \%$ infection compared to 'Danvers 126', 'Py-60', and 'Spartan Bonus 80', which averaged 33.3\% infection.

Limited research has been conducted on controlling carrot pests genetically. Angell and Gabelman (1968) demonstrated that resistance to leaf spot fungus (Cercospora carotae) was controlled by a single gene. Resistance to the root-knot nematodes Meloidogyne incognita and $M$. hapla seems to be quantitatively inherited (Huang et al., 1986; Wricke et al., 1985). P. Simon and J.O. Strandberg (personal communication) have demonstrated a pattern of quantitative inheritance for resistance to alternaria leaf blight (Alternaria dauci) in carrot. Ellis (1992) reported little progress using recurrent selection for developing carrot-fly (Psila rosae $\mathrm{F}$.) resistant lines. Our data suggest that resistance to carrot aster yellows may be a quantitatively inherited trait because of the distribution of phenotypic values and environmental interaction measured among carrot lines.

Resistance to carrot aster yellows was detected among inbred lines and hybrids evaluated in this investigation as compared to standard carrot cultivars. These inbred lines represent the first known carrot germplasm with resistance to aster yellows. Data from this investigation support the notion that inbreeding helps develop pest-resistant inbred lines from cross-pollinated crops. Results from this study suggest that resistant lines may be used in carrot production to reduce the dependence on insecticides to control the aster leafhopper in the midwestern United States.

\section{Literature Cited}

Angell, F.F. and W.H. Gabelman. 1968. Inheritance of resistance in carrot, Daucus carota var. sativa, to the leaf spot fungus Cercospora carotae. Proc. Amer. Soc. Hort. Sci. 93:434-437.

Arcelin, R. and A.C. Kushalappa. 1991. A survey of carrot diseases on muck soils in the southwestern part of Quebec. Can. Plant Dis. Survey 71(2):147-153.

Braun, E.J. and W.A. Sinclair. 1976. Histopathology of phloem necrosis in Ulmus americana. Phytopathology 66:598-607.

Chiykowski, L.N. 1967. Reaction of some wheat varieties to aster yellows virus. Can. J. Plant Sci. 47:149-151.

Chiykowski, L.N. 1977. Reduction in the transmissibility of a greenhouse-maintained isolate of aster yellows agent. Can J. Bot. 55:1783- 
1786.

Chiykowski, L.N. 1978. Delayed expression of aster yellows symptoms in celery. Can. J. Bot. 56:2987-2989.

Chiykowski, L.N. 1987. Aster yellows in strawberry. U.S. Dept. Agr. Hdbk. Virus Diseases of Small Fruits 631:31-34.

Chiykowski, L.M. and R.K. Chapman. 1965. Migration of the six-spotted leafhopper in Central North America. Univ. Wisconsin Agr. Expt. Sta. Res. Bul. 261:21-45.

Ellis, N. 1992. Breeding carrots resistant to carrot fly. The Horticulturist $1(2): 2-4$

Girolami, G. 1955. Comparative anatomical effects of the curly-top and aster-yellows viruses on the flax plant. Bot. Gaz. 116:305-322.

Huang, S.P., P.T. Della Vecchia, and P.E. Ferreira. 1986. Varietal response and estimates of heritability of resistance to Meloidogyne javanica in carrots. J. Nematol. 18:496.

Kunkel, L.O. 1926. Studies on aster yellows. Amer. J. Bot. 13:646-705. Linn, M.B. 1940. The yellows disease of lettuce and endive. New York Agr. Expt. Sta. Bul. 742.

McCoy, R.E. 1979. The mycoplasmas. vol. 3. Academic Press. p. 229-
264

Peterson, A.G. and R.S. Saini. 1964. Relation of aster yellows infection in host plants to increase of six-spotted leafhopper. Proc. North Central Branch Entomol. Soc. Amer. 19:99.

Schultz, G.A. 1973. Plant resistance to aster yellows. Proc. North Central Branch Entomol. Soc. Amer. 28:93-99.

Struckmeyer, B.E. 1963. The anatomic responses of Daucus carota to the aster yellows virus. Amer. J. Bot. 50(9):959-963.

Wricke, G., L. Frese, M. Sandmann, and C. Kraus. 1985. Genetic and epidemiological investigations on the resistance of carrot, Daucus carota $\mathrm{L}$. to the northern root-knot nematode, Meloidogyne hapla Chitwood. Schritt. Deutschn Forsch. p. 1.

Zalom, F.G. 1981. The influence of reflective mulches and lettuce types on the incidence of aster yellows and abundance of its vector, Macrosteles fascifrons (homoptera: cicadellidae), in Minnesota. Great Lakes Entomol. 14(3):145-151.

Zelcer, A., G. Loebenstein, and M. Bar-Joseph. 1972. Effects of elevated temperature on the ultrastructure of mycoplasma-like organisms in periwinkle. Phytopathology 62:1453-1457. 